\title{
Mini-incision cataract surgery and toric lens implantation for the reduction of high myopic astigmatism in patients with pellucid marginal degeneration
}

A Balestrazzi', S Baiocchi', A Balestrazzi², G Cartocci', GM Tosi', G Martone ${ }^{1}$ and $\mathrm{P}$ Michieletto ${ }^{2}$

\begin{abstract}
Purpose To evaluate the clinical outcomes, safety, and efficacy of cataract surgery with the implantation of a toric intraocular lens (IOL) in eyes with stable pellucid marginal degeneration (PMD).

Methods Eleven eyes (eight patients) diagnosed as stable PMD and cataract underwent mini-incision $2.2 \mathrm{~mm}$ cataract surgery followed by the implantation of hydrophobic toric aspheric IOL (AcrySof IQ Toric IOL, Alcon, Fort Worth, TX, USA). Perioperative variables of interest included uncorrected (UDVA) and corrected (CDVA) distance visual acuities, manifest refraction, and corneal topography. Paired samples $t$-tests were used to analyze preoperative and postoperative visual acuity, astigmatism, and spherical equivalent (SE) parameters. Follow-up was 6 months.

Results The mean CDVA was $0.62 \pm 0.26$ $\log$ MAR preoperatively and $0.07 \pm 0.07$ logMAR postoperatively. The mean preoperative sphere and cylinder was
\end{abstract} $-3.14 \pm 3.58 \mathrm{D}$ and $-4.84 \pm 2.02 \mathrm{D}$, respectively. The mean postoperative manifest refractive sphere and cylinder was $-0.30 \pm 0.51 \mathrm{D}$ and $-0.81 \pm 1.51 \mathrm{D}$, respectively. There was a significant reduction in refractive astigmatism after toric IOL implantation $(P<0.002)$. The toric IOL axis rotation was $<5^{\circ}$ in all cases at the final follow-up.

Conclusions Implantation of hydrophobic toric IOL was a safe and effective surgical procedure to correct mild to moderate stable PMD.

Eye (2015) 29, 637-642; doi:10.1038/eye.2015.13; published online 27 February 2015
Introduction

Pellucid marginal degeneration (PMD) is an idiopathic, noninflammatory thinning disorder normally involving the inferior peripheral part of the cornea, concentric with the limbus, between the 4 and $8 o^{\prime}$ clock meridians. The onset of the disease is usually between the ages of 20 and 40 years. The zone of thinning is generally $1-2 \mathrm{~mm}$ wide, and separated 1 or $2 \mathrm{~mm}$ from the limbus by an area of normal cornea. The area of ectasia is cylindrical, rather than conic as in keratoconus, and occurs just above, rather than inside, the area of greatest thinning creating an against the rule astigmatism. ${ }^{1,2}$

Management of affected patients depends on the level of visual disability and can be organized in structural, partial-thickness, fullthickness, and corneal-independent interventions. $^{3}$

Structural interventions include techniques designed to strengthen the structure of the corneal stroma, such as corneal collagen crosslinking $(\mathrm{CXL}){ }^{4}$ or techniques designed to modify the curvature and the mechanical properties of the corneal stroma, such as intrastromal corneal ring segments (ICRS). ${ }^{5}$ Partial-thickness techniques comprise interventions involving the removal of only the anterior layer of the abnormally thinned cornea, with partial cornea replacement or the removal of the total cornea preserving the host endothelium. Full-thickness interventions include the removal of only the abnormally thinned cornea, or of the total cornea with the replacement of all cornea layers.
${ }^{1}$ Ophthalmology Unit, Department of Medicine, Surgery and Neuroscience, University of Siena, Siena, Italy

${ }^{2}$ Department of Medicine, Surgery and Neuroscience, Ophthalmic Hospital, Rome, Italy

Correspondence: A Balestrazzi, Dipartimento di Scienze Mediche, Chirurgiche e Neuroscienze, Università di Siena, Viale Bracci 1, Siena 53100, Italy Tel: +390577 585660; Fax: +390577586162. E-mail: angelo.balestrazzi@ unisi.it

Received: 29 August 2014 Accepted in revised form: 24 December 2014 Published online: 27 February 2015 
Corneal independent interventions involve the use of lenses and comprise spectacles and contact lenses (nonsurgical) and toric, phakic, and pseudophakic intraocular lenses (IOLs).

Some authors proposed the implantation of toric phakic iris-fixated IOL (Verisyse/Artisan). ${ }^{6}$ Others reported a case in which toric intraocular posterior chamber phakic Collamer lenses (ICL) effectively corrected the refractive errors of PMD. ${ }^{7}$

The toric IOL was devised by Shimizu et $a l^{8}$ in 1994 and has been used clinically since then. Previous studies have analyzed the results of several toric IOL implantations after cataract surgery and have shown good rotational stability and good functional results. ${ }^{9,10}$

The aim of this study is to evaluate the efficacy of a toric IOL (AcrySof IQ Toric IOL, Fort Worth, TX, USA) implanted after a conventional phacoemulsification in order to reduce the high myopic astigmatism in patients with PMD.

\section{Materials and methods}

This prospective interventional study enrolled 8 patients (11 eyes), from January 2012 to December 2013, who had preoperative PMD and cataract diagnosis. All consecutive cases with PMD and cataract underwent a $2.2 \mathrm{~mm}$ microincision cataract surgery and implantation of toric IOL. All surgeries were performed by three experienced surgeons (SB, AB, and P.M), at the Ophthalmology Unit, Department of Medicine, Surgery and Neuroscience, University of Siena, Siena, and at the Ophthalmic Hospital, Rome, Italy.

The study was carried out in accordance with the Declaration of Helsinki, and the protocol was approved by the Institute Board of each of the two Hospitals.

The inclusion criteria were as follows: patients with lens opacities, between 50 and 80 years of age, topographical stability of the corneal ectasia in the year before surgery (progression was diagnosed by an increase $>0.50 \mathrm{D}$ in cylinder or changes in axis or an increase in the corneal apex $\mathrm{K}$ value $>1.00 \mathrm{D}$ ). Exclusion criteria included previous ocular trauma, amblyopia, anterior segment pathology other than PMD, and cataract, posterior segment pathology other than myopia.

The patients were provided with comprehensive counselling preoperatively, including a full explanation of the misalignment risks of the toric IOL, of the postoperative risks for rotational stability of the IOL and of the positive chances of needing IOL explantation in addition to the normal risks associated with cataract surgery. In particular, patients were informed of the paucity of literature regarding the use of the toric IOL in patients with PMD.

\section{Preoperative evaluation}

Preoperatively, patients had a complete ophthalmologic examination including corrected distance visual acuity (CDVA), manifest refraction by autorefraction (RM8800, Topcon, Tokyo, Japan), Javal-Schiotz keratometry, corneal topography, (Keratron, Optikon, Rome, Italy), and optical pachymetry by Visante OCT (Zeiss Meditec, Jena, Germany). Figure 1 shows the corneal topography of two patients.

Biometry was performed with optical coherence biometry (IOL master; Carl Zeiss Meditec, Jena, Germany) using the Haigis formula for the IOL power calculation and the A-constant of 118.7 for the toric IOL. Data for the IOL calculation were taken from direct use of the IOL master. The target postoperative spherical equivalent was emmetropia. IOL cylinder power and alignment axis were calculated using a program available from the IOL manufacturer (www. acrysoftoriccalculator.com), taking into account the topographic keratometry readings as well as the mandatory data input on the rotation of the IOL and the estimate of surgically induced astigmatism from the temporal incision (0.25D).

\section{Surgical technique}

Before surgery, the slitlamp with the beam oriented horizontally was used to mark the limbus. These were then used as references. Intraoperatively, the actual implantation axis was marked using a Mendez ring and a toric axis marker (AE-2740; ASICO, Westmont, IL, USA). Cataract surgery was performed under topical anesthesia (10\% Ropivacaine). Each patient underwent microincision cataract surgery using the Infinity Vision System and OzilTM Torsional Handpiece (Alcon, Fort Worth, TX, USA) with a $2.2 \mathrm{~mm}$ temporal clear corneal incision. The toric IOL was implanted into the capsular bag with a Monarch injector and a D-Cartridge (Alcon, Fort Worth, TX, USA). The IOL was rotated to its final position by exactly aligning the toric reference dots with the limbal implantation axis marks. Stromal hydration was performed to achieve wound integrity, and a small bolus of intracameral cefuroxime ( $1 \mathrm{mg}$ in $0.1 \mathrm{ml}$ of sterile balanced salt solution) was administered through one of the paracenteses.

\section{Postoperative evaluation}

All eyes were examined postoperatively at 1 day, 1 week, and 1 and 6 months. The examinations included uncorrected distance visual acuity (UDVA), CDVA, manifest refraction, intraocular pressure, and IOL vaulting. Outcome measures were recorded at the last 


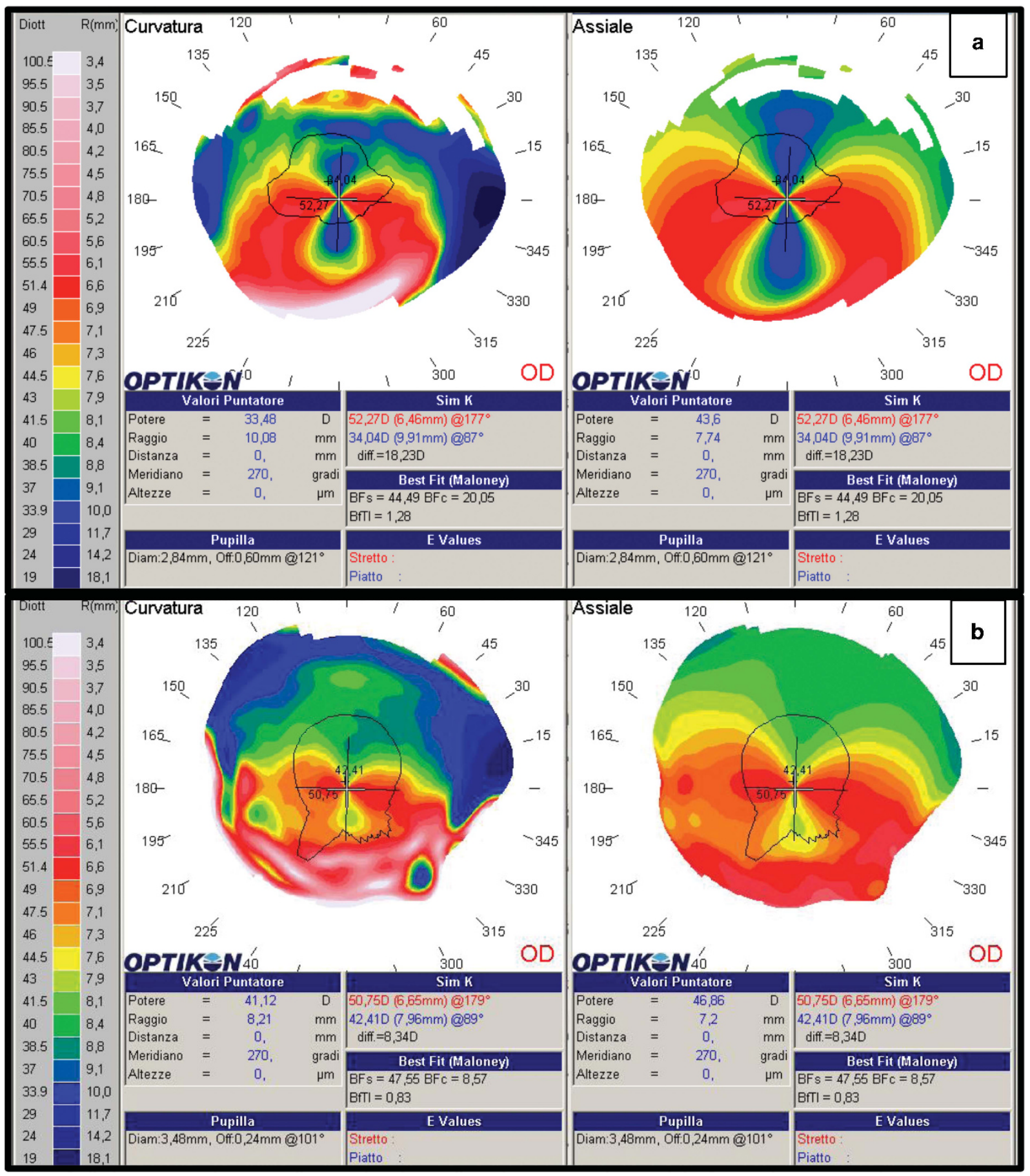

Figure 1 Corneal topography of 2 patients with PMD: case 7 (a) and case 8 (b).

postoperative visit and included UDVA, CDVA, manifest refraction, and corneal topography, performed using the same devices as preoperatively. After surgery, patients were invited to complete a short survey detailing the quality of their vision, the presence of glare, halos, or other symptoms, and the overall satisfaction with the procedure.

\section{Statistical analysis}

All data were collected in an Excel database (Microsoft Office for Mac 2011; Microsoft, Redmond, WA, USA) and analyzed with SPSS for Mac (version 16.0, SPSS Inc., Chicago, IL, USA). Snellen UDVA and CDVA were converted into LogMAR for the mathematical and 
statistical calculations. The mean and SEM were calculated for the following variables: age, preoperative and postoperative CDVA, preoperative spherical equivalent (SE), postoperative SE, and postoperative UDVA. Paired samples $t$-tests were used to analyze preoperative and postoperative visual acuity, astigmatism and SE parameters. Differences were considered statistically significant when the $P$-value was $<0.05$.

\section{Results}

This study evaluated 11 eyes of 8 patients with PMD. The mean age of the five men $(62.5 \%)$ and three women $(37.5 \%)$ was $68.8 \pm 8.1$ years.

The mean CDVA was $0.62 \pm 0.26 \log$ MAR preoperatively and $0.07 \pm 0.07 \log$ MAR postoperatively. The mean postoperative UDVA was $0.26 \pm 0.24 \log$ MAR (Figure 2). There was a statistically significant increase in CDVA after toric IOL implantation $(P<0.0005)$. The postoperative CDVA was $0.00 \log$ MAR in four eyes $(36.3 \%)$ and $0.20 \log$ MAR or better in all eyes (Figure 2 ). The mean preoperative keratometric cylinder measured by corneal topography was $-4.74 \pm 1.86 \mathrm{D}$ (Figure 3 ). The mean preoperative manifest sphere and cylinder was $-3.14 \pm 3.58 \mathrm{D}$ and $-4.84 \pm 2.02 \mathrm{D}$, respectively. The mean postoperative manifest sphere and cylinder refraction was $-0.30 \pm 0.51 \mathrm{D}$ and $-0.81 \pm 1.51 \mathrm{D}$, respectively. There was a significant reduction in refractive astigmatism after toric IOL implantation $(P<0.002)$.

The mean preoperative $\mathrm{SE}$ in all 11 eyes was $-4.42 \pm 5.19 \mathrm{D}$ (Figure 3). At the last visit the mean postoperative SE was $-0.23 \pm 0.27 \mathrm{D}$. The difference between preoperative and postoperative SE was statistically significant $(P=0.012)$. SE was within $0.25 \mathrm{D}$ of plano in eight eyes (72.8\%), from 0.25 to $0.50 \mathrm{D}$ of plano in two eyes $(18.2 \%)$, and within $0.75 \mathrm{D}$ of emmetropia in one eye $(9 \%)$.

Corneal astigmatism did not significantly change following surgery.

The toric IOL axis rotation was $<5^{\circ}$ in all cases at final follow-up.

All eight patients reported improvement to distance and night vision and were overall satisfied with the outcome of the surgery. Table 1 shows patient demographics, preoperative, and postoperative data.

\section{Discussion}

Many options exist for the treatment of early and moderate PMD. Most patients with PMD are treated nonsurgically with spectacles or contact lenses. Soft and hybrid contact lenses can be used in early PMD, but lose

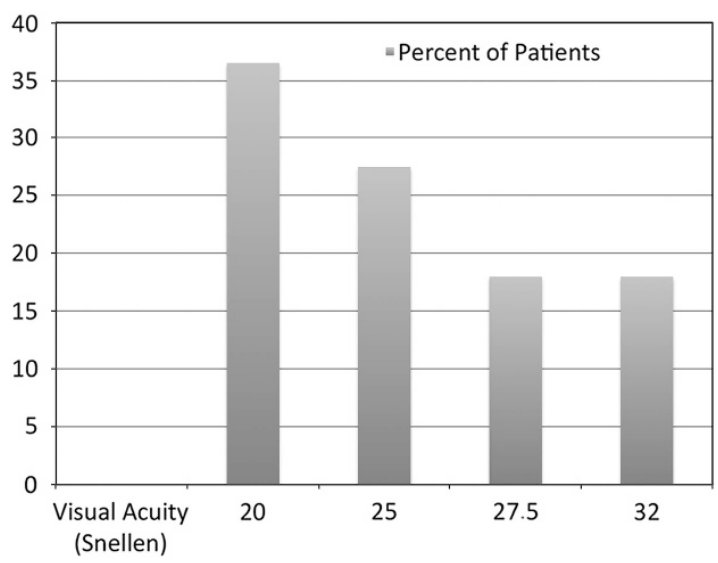

Figure 2 Postoperative CDVA.

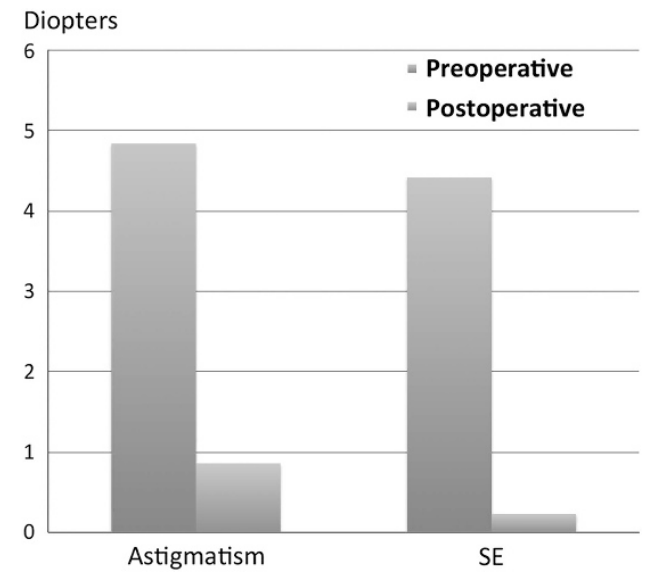

Figure 3 Comparison of mean preoperative and postoperative astigmatism and spherical equivalent.

their effectiveness as the disease progresses. In moderate PMD, the development of irregular astigmatism and progressive corneal irregularity often necessitates the use of large diameter rigid gas permeable lenses. ${ }^{9-11}$

Toric IOLs can be implanted in either the anterior or the posterior chamber, either with or without natural lens extraction (toric phakic IOLs (PIOLs)), and allow for the correction of refractive error and astigmatism independent of cornea alterations. ${ }^{3}$

Camoriano et $a l^{12}$ recently reported improved visual acuity and astigmatism with toric PIOL implantation for PMD in 10 eyes with severe glare and halos requiring removal in only 1 eye.

A significant share of patients with cataract will have some naturally occurring astigmatism, and the safety and efficacy of treating this with modern toric IOL technology 
Table 1 Patient demographics, preoperative, and postoperative data

\begin{tabular}{|c|c|c|c|c|c|c|c|c|c|}
\hline \multirow{2}{*}{ Patients } & \multirow{2}{*}{ Age (years) } & \multirow{2}{*}{ Eye } & \multirow{2}{*}{ Sex } & \multicolumn{3}{|c|}{ Preoperative } & \multicolumn{3}{|c|}{ Postoperative } \\
\hline & & & & Refraction & $C D V A(\log M A R)$ & $I O L$ & Refraction & UDVA & $C D V A$ \\
\hline 1 & 62 & $\mathrm{R}$ & $\mathrm{F}$ & $-4.50-3.50 \times 95^{\circ}$ & 0.54 & SN6AT8 & -0.25 & 0.1 & 0.1 \\
\hline 1 & 62 & $\mathrm{~L}$ & $\mathrm{~F}$ & $-5.00-3.25 \times 105^{\circ}$ & 0.40 & SN6AT6 & $-0.50 \times 95^{\circ}$ & 0.05 & 0.00 \\
\hline 2 & 69 & $\mathrm{~L}$ & $\mathrm{~F}$ & $+0.50-5 \times 90^{\circ}$ & 0.40 & SN6AT9 & $+0.25-0.75 \times 90^{\circ}$ & 0.3 & 0.05 \\
\hline 3 & 71 & $\mathrm{~L}$ & M & $-0.75-2 \times 90^{\circ}$ & 0.40 & SN6AT4 & $-0.75 \times 70^{\circ}$ & 0.3 & 0.05 \\
\hline 4 & 77 & $\mathrm{~L}$ & $\mathrm{~F}$ & $-5-3.75 \times 80^{\circ}$ & 0.40 & SN6AT7 & $-0.25-0.50 \times 180^{\circ}$ & 0.18 & 0.05 \\
\hline 4 & 77 & $\mathrm{R}$ & $\mathrm{F}$ & $-3.25-3.25 \times 80^{\circ}$ & 0.40 & SN6AT6 & 0 & 0.00 & 0.00 \\
\hline 5 & 73 & $\mathrm{R}$ & M & $-5 \times 90^{\circ}$ & 0.70 & SN6AT8 & $+0.50 \times 170^{\circ}$ & 0.05 & 0.00 \\
\hline 5 & 73 & $\mathrm{~L}$ & M & $-0.25-7.50 \times 80^{\circ}$ & 1.00 & SN6AT9 & $+0.75-2 \times 80^{\circ}$ & 0.4 & 0.1 \\
\hline 6 & 79 & $\mathrm{~L}$ & M & $-2.25-4 \times 90^{\circ}$ & 0.54 & SN6AT7 & $+0.50+0.50 \times 5^{\circ}$ & 0.2 & 0.1 \\
\hline 7 & 59 & $\mathrm{R}$ & M & $-2-8.50 \times 85^{\circ}$ & 1.00 & SN6AT9 & $+1.25-4 \times 90^{\circ}$ & 0.7 & 0.2 \\
\hline 8 & 55 & $\mathrm{R}$ & M & $-12-7 \times 90^{\circ}$ & 1.00 & SN6AT9 & $+1-390^{\circ}$ & 0.7 & 0.2 \\
\hline
\end{tabular}

is well established. The use of toric IOLs to treat nonnaturally occurring astigmatism has been reported. ${ }^{13,14}$

Unusual clinical conditions have been treated with toric IOL technology. A hydrophilic acrylic with hydrophobic surface toric IOL was used to correct astigmatism in 12 cases of stable mild to moderate keratoconus and cataract, after phacoemulsification with good results. ${ }^{15}$ More recently a single-piece acrylic toric IOL was used to correct astigmatism in 17 cases of forme fruste keratoconus, after microincision bimanual cataract surgery, with good results. ${ }^{16}$ Refractive lens exchange with Acrysof toric IOL implantation was also proposed in patients with nonprogressive keratoconus. ${ }^{17}$

Moreover, in case of simultaneous presence of stable PMD and cataract, Luck ${ }^{18}$ proposed the use of a customized ultrahigh-power IOL implantation in a 41-year-old patient, with encouraging results.

On the basis of these studies, in this prospective interventional study a population of patients with simultaneous stable PMD and cataract was treated with a $2.2 \mathrm{~mm}$ phacoemulsification followed by implantation of a toric aspheric hydrophobic IOL (AcrySof IQ Toric IOL). In these patients, the risk for progression, due to the PMD pattern and the patients' age, is extremely low.

Regarding the visual results, a significant improvement in UDVA, CDVA, cylinder, and SE reduction was found. Eyes in our study had an $83.3 \%$ mean reduction in astigmatism after AcrySof toric IOL implantation. Our results are almost comparable to the results obtained with the same technique employed in regular corneal astigmatism. ${ }^{19}$

Regarding the refractive results, the accuracy achieved in our case series was particularly high. This finding could be explained by the PMD refractive peculiarity compared with keratoconus. Aliò et al ${ }^{15}$ stated that a factor that should influence the refractive result is the location of the ectasia. Aliò also stated that paracentral ectasias affect less the keratometric readings in the visual axis zone and therefore a better accuracy in the calculation of the toric IOL is expected. ${ }^{15}$

In line with Aliò et al, and despite several studies report encouraging results after the implantation of toric IOLs in case of stable mild keratoconus, in our opinion it is still difficult to measure with precision the keratometric readings in keratoconus patients. In fact, because of several different keratoconus patterns and of the weak correlation between subjective astigmatism, keratometry, corneal topography, autorefractometry, and optical coherence biometry, ${ }^{19}$ the keratometric readings and axis values cannot be established with absolute certainty. As a consequence, incorrect toric IOL positions during the surgery can occur.

On the other hand, PMD is a peripheral ectatic disorder. Peripheral ectasia affects the keratometric readings and regularity to a lesser extent than keratoconus, and the values obtained with different instruments are more comparable and repeatable.

The precision of the toric IOL calculation in mild-tomoderate stable PMD, could explain the good results obtained in our study.

In conclusion, although the number of cases analyzed in this study is not high, this is, to the best of our knowledge, the largest series of PMD cataractous patients implanted with toric IOLs after mini-incision $2.2 \mathrm{~mm}$ phacoemulsification. The results from our study demonstrate that this technique is a safe, predictable and effective surgical option in nonprogressive PMD.

Prospective comparative studies with larger samples should continue evaluating the efficacy of this procedure. 


\section{Summary}

\section{What was known before}

- Toric IOL has obtained important results in concomitant regular astigmatism and cataract.

- This kind of IOL has also been proposed for irregular astigmatism due to keratoconus, with good results.

\section{What this study adds}

- This is the first case series that investigates the use of toric IOLs in case of concomitant PMD and cataract.

- In this case the results seems to be relevant and better if compared with keratoconus results.

- The reason of these results could be explained by the good regularity of the central part of the cornea that distinguish pellucid degeneration if compared with keratoconus.

\section{Conflict of interest}

The authors declare no conflict of interest.

\section{References}

1 Krachmer JH. Pellucid marginal corneal degeneration. Arch Ophthalmol 1978; 96: 1217-1221.

2 Sridhar MS, Mahesh S, Bansal AK, Nutheti R, Rao GN. Pellucid marginal corneal degeneration. Ophthalmology 2004; 111: 1102-1107.

3 Moshirfar M, Edmonds JN, Behunin NL, Christiansen SM. Current options in the management of pellucid marginal degeneration. I Refract Surg 2014; 30: 474-485.

4 Spadea L. Corneal collagen cross-linking with riboflavin and UVA irradiation in pellucid marginal degeneration. J Refract Surg 2010; 26: 375-377.

5 Piñero DP, Alio JL. Intracorneal ring segments in ectatic corneal disease-a review. Clin Experiment Ophthalmol 2010; 38: 154-167.

6 de Vries NE, Tahzib NG, Webers CA, Hendrikse F, Nuijts RM. Use of Verisyse/Artisan phakic intraocular lens for the reduction of myopia in a patient with pellucid marginal degeneration. Cornea 2008; 27: 241-245.

7 Kamiya K, Shimizu K, Hikita F, Komatsu M. Posterior chamber toric phakic intraocular lens implantation for high myopic astigmatism in eyes with pellucid marginal degeneration. J Cataract Refract Surg 2010; 36: 164-166.

8 Shimizu K, Misawa A, Suzuki Y. Toric intraocular lenses: correcting astigmatism while controlling axis shift. J Cataract Refract Surg 1994; 20: 523-526.

9 Horn JD. Status of toric intraocular lenses. Curr Opin Ophthalmol 2007; 18: 58-61.

10 Tzelikis PF, Cohen EJ, Rapuano CJ, Hammersmith KM, Laibson PR. Management of pellucid marginal corneal degeneration. Cornea 2005; 24: 555-560.

11 Kompella VB, Aasuri MK, Rao GN. Management of pellucid marginal corneal degeneration with rigid gas permeable contact lenses. CLAO J 2002; 28: 140-145.

12 Camoriano GD, Aman-Ullah M, Purba MK, Sun J, Gimbel HV. Toric collagen copolymer phakic intraocular lens to correct my- opic astigmatism in eyes with pellucid marginal degeneration. J Cataract Refract Surg 2012; 38: 256-261.

13 Nanavaty MA, Lake DB, Daya SM. Outcomes of pseudophakic toric intraocular lens implantation in keratoconic eyes with cataract. J Refract Surg 2012; 28 884-889.

14 Buchwald HJ, Lang GK. [Cataract surgery with implantation of toric silicone lenses for severe astigmatism after keratoplasty]. Klin Monbl Augenheilkd 2004; 221: 489-494.

15 Alió JL, Peña-García P, Abdulla Guliyeva F, Soria FA, Zein G, Abu-Mustafa SK. MICS with toric intraocular lenses in keratoconus: outcomes and predictability analysis of postoperative refraction. Br J Ophthalmol 2014; 98: 365-370.

16 Jaimes M, Xacur-García F, Alvarez-Melloni D, Graue-Hernández EO, Ramirez-Luquín T, Navas A. Refractive lens exchange with toric intraocular lenses in keratoconus. J Refract Surg 2011; 27: 658-664.

17 Luck J. Customized ultra-high-power toric intraocular lens implantation for pellucid marginal degeneration and cataract. J Cataract Refract Surg 2010; 36: 1235-1238.

18 Kim MH, Chung TY, Chung ES. Long-term efficacy and rotational stability of AcrySof toric intraocular lens implantation in cataract surgery. Korean J Ophthalmol 2010; 24: $207-212$.

19 Davis LJ, Schechtman KB, Begley CG, Shin JA, Zadnik K. Repeatability of refraction and corrected visual acuity in keratoconus. The CLEK Study Group. Collaborative Longitudinal Evaluation of Keratoconus. Optom Vis Sci 1998; 75: 887-896. 